\title{
Duodenoscopic appraisal of duodenal ulcer in dogs
}

\author{
Mani Saravanan¹, B. Nagarajan², S. Kavitha², C. Balachandaran³, S. R. Srinivasan ${ }^{4}$ \\ 1. Indian Veterinary Research Institute, Izatnagar, 243122 (U.P) India; 2. Department of Veterinary \\ Clinical Medicine Ethics and J urisprudence Madras Veterinary College, Chennai; 3. Registrar, TANUVAS \\ Chennai- 600 051; 4. Directorate of Distance education, TANUVAS Chennai- 600051 \\ Corresponding author: Mani Saravanan, email:sara82vet@yahoo.com \\ Received: 20-02-2012, Accepted: 29-02-2012, Published Online: 17-04-2012 \\ doi: $10.5455 /$ vetworld.2012.420-423
}

\begin{abstract}
Aim: To assess the usefulness of duodenoscopy in the diagnosis of duodenal ulcers in dogs.

Materials and Methods: Sick dogs with chronic gastrointestinal problems were physically examined and samples were collected for haematology, biochemistry and faecal examination. Duodenal biopsies, duodenal contents and brush cytology were obtained via duodenoscopy.

Results: Seven duodenal ulcers cases were recorded, higher incidences was recorded in Labrador retriever, 2-4 years of aged male dogs. Significantly decreased $\mathrm{Hb}(9.10 \pm 0.25 \mathrm{~g} / \mathrm{dl})$, RBCs $(4.39 \pm 0.19 \mathrm{mill} / \mathrm{cu} . \mathrm{mm})$ and albumin $(2.343 \mathrm{~b} \pm 0.13 \mathrm{~g} / \mathrm{dl})$ level were noticed. Hyperaemia with ulceration of duodenal mucosa was observed.

Conclusion: Duodenoscopy is very much useful for detection of duodenal ulceration and provided a sensitive technique for early diagnosis of mucosal lesions and ulceration.

Key words: Dog, Duodenal ulcer, Duodenoscopy

\section{To cite thisarticle:}

Saravanan M, Nagarajan B, Kavitha S, Balachandaran C, Srinivasan SR (2012) Duodenoscopic appraisal of duodenal ulcer in dogs, Vet World, 5(7):420-423, doi: 10.5455/vetworld.2012.420-423
\end{abstract}

\section{I ntroduction}

A chronic small intestinal disorder of dog is the major contributor to canine gastrointestinal disorders. The majority of small intestinal disorders are occurring in the duodenum such as ulcer, inflammatory bowel disease (IBD) and small intestinal bacterial overgrowth (SIBO) [1]. Factors like ulcerogenic drugs, stress factors, neurological disease, entrogastric reflux, renal disease, hepatic disease, mucosal ischemia, primary gastroduodenal neoplasia, mastrocytoma and gastrinoma were associated with development of gastroduodenal ulceration and erosions [2]. Duodenal ulcers are difficult to identify clinically because of the non-specific symptoms. They may or may not be identifiable through routine radiographic, ultrasonographic or laboratory evaluation methods, because many diseases of duodenum primarily involve the mucosal surface [3].

Endoscopic examination of the upper gastrointestinal tract has been used increasingly as a diagnostic tool in small animal practice. Use of this procedure has led to an early diagnosis of chronic gastrointestinal disease and better understanding of their pathophysiology [4]. Duodenoscopy is an efficient way of identifying the abnormalities of proximal small intestinal mucosa including mucosal irregularities, distortion, ulceration, neoplasia, inflammation and other mucosal disorders of the duodenum [5]. Duodensocopy is also useful for obtaining mucosal biopsy and duodenal juice for routine histopathological and bacteriological studies [6]. The aim of the study was to assess the usefulness of duodenoscopy in the diagnosis of duodenal ulcer in dogs.

\section{Materials and Methods}

The study has been conducted in clinical cases and no such experimental model has been created / used in this study. The endoscopic procedure and collection of biopsy, cytology and duodenal contents were done aseptically following standard procedure as per CPCSEA norms.

The study was conducted at the Department of Veterinary Clinical Medicine, Ethics and Jurisprudence, Madras Veterinary College Teaching Hospital, Chennai. Apparently healthy dogs submitted for routine clinical examinations were randomly selected to obtain normal data for the parameters under study. Dogs with 
Table-1. Mean \pm SE of Haemato- biochemical and Bacterial colony counts in healthy and diseased animals

\begin{tabular}{lll}
\hline Parameters & Healthy & Duodenal ulcer \\
\hline $\mathrm{Hb}$ g/ dl & $12.33^{\mathrm{a}} \pm 0.61$ & $9.10^{\mathrm{b}} \pm 0.25^{* *}$ \\
PCV \% & $39.83 \pm 0.53$ & $36.143 \pm 3.27$ \\
$\mathrm{RBC}(\mathrm{mill} / \mathrm{cu} . \mathrm{mm})$ & $6.48^{\mathrm{a}} \pm 0.26$ & $4.39^{\mathrm{b}} \pm 0.19^{* *}$ \\
$\mathrm{MCV}(\mathrm{fl})$ & $61.29 \pm 2.31$ & $58.84 \pm 0.007$ \\
$\mathrm{MCH}(\mathrm{pg})$ & $17.90 \pm 1.89$ & $20.24 \pm 0.79$ \\
$\mathrm{MCHC}(\%)$ & $32.29 \pm 1.61$ & $27.82 \pm 2.83$ \\
Platelets X $10^{5} / \mathrm{ll}$ & $1.984 \pm 0.09$ & $1.42 \pm 0.03$ \\
BUN (mg/dl) & $20.68 \pm 1.82$ & $22.28 \pm 2.85$ \\
Creatinine (mg/dl) & $0.823 \pm 0.06$ & $1.16 \pm 0.22$ \\
ALT (IU/L) & $44.973 \pm 6.92$ & $45.379 \pm 7.01$ \\
ALP (IU/L) & $64.24 \pm 7.57$ & $68.64 \pm 3.80$ \\
Total Protein (g/dl) & $6.17 \pm 0.26$ & $6.54 \pm 0.48$ \\
Albumin (g/dl) & $3.00^{\mathrm{a}} \pm 0.21$ & $2.343^{\mathrm{b}} \pm 0.13^{*}$ \\
Globulin (g/dl) & $3.142 \pm 0.11$ & $4.197 \pm 0.53$ \\
Bacterial counts $\times 10^{5} \mathrm{cfu} / \mathrm{ml}$ & $0.98 \pm 0.03$ & $0.96 \pm 0.04$ \\
\hline
\end{tabular}

Means showing the same superscript in the column do not differ significantly** - Highly Significant. $(P \leq 0.01) *$ - significant $(P \leq 0.05)$

clinical signs persistent/ chronic intermittent vomiting, diarrhoea, haematemesis and melena (for more than three days) suggestive of gastrointestinal disease were physically examined and samples taken for hematology, biochemistory and fecal examination. Duodenal biopsies, duodenal contents and brush cytology were obtained via gastroduodenoscopy.

Duodenoscopic study was conducted with Video endoscope, Karl Storz type No. 60914 PKS (Germany), with an outer diameter of $9.8 \mathrm{~mm}$, biopsies channel diameter of $2.8 \mathrm{~mm}$ and endoscopic images were captured digitally by using the software of IMIMO. Preparation and restraining of the patient was done as suggested by Zoran [3] and Tams [7]. Four to six representative biopsy samples were taken by using pinch biopsy forceps [8] and samples were processed for histopathological examination as per Sancho et al. [9] and interpretation as per Day et al.[10].

Brush cytology smears were collected by cytology brushes enclosed in a plastic protective sheath and the smear stained with Giemsa. About $0.25 \mathrm{ml}$ to $1.0 \mathrm{ml}$ of duodenal contents was collected in a sterile test tube by a sterile plastic catheter inserted through an endoscope operating channel [11]. The collected duodenal contents $(0.1 \mathrm{ml})$ were serially diluted up to $10^{6}$ for aerobic culture and $0.1 \mathrm{ml}$ of each dilution transferred to nutrient agar plates and incubated at $35^{\circ} \mathrm{C}$ for $24 \mathrm{hrs}$ and bacterial colonies were counted with colony counter [12]. The collected duodenal contents were cultured for isolation and quantification of bacteria. Faecal samples were also collected and subjected to gross and microscopic examination as per Broussard [13]. The data obtained in this study were analysed by using Independent sample test [14].

\section{Results and Discussion}

Total number of dogs brought to Madras Veterinary College Teaching Hospital irrespective of nature of diseases were 22,240 during the course of the study (two semesters). 3610 (16.8\%) dogs had gastro intestinal disorders and 7 cases $(0.19 \%)$ had duodenal ulcers. In the present study male dogs had more incidence and most of the duodenal ulcers were found in 2-4 years of age. There was no apparent sex predilection in duodenal ulcer [15]. Breed wise Labrador Retrievers (57\%) followed by mongrels (29\%) and Boxer (14\%). Breeds commonly affected with duodenal ulcer were mixed breeds [15], Labrador Retriever, Rottweiler and Dobermann [16].

All the seven dogs showed vomiting as a predominant clinical sign followed by anorexia (57\%), weight loss and abdominal pain (43\% each), lethargy and haematemesis (28\%each). Diarrhoea, dehydration anaemia, melena, smell in faeces and previous treatment of Non-steroid anti-inflammatory drugs $(14 \%$ each) were also recorded in duodenal ulcers. These findings were similar to the observations of various authors who documented clinical signs such as vomiting, weight loss and abdominal pain 15 , haematemesis, anaemia and abdominal pain [17]. Leib and Matz [18] stated that these signs were because of gastrointestinal haemorrhage due to ulceration.

The mean \pm SE of haematology, serum biochemical and bacterial count values are given in Table-1. Highly significant decrease in haemoglobin and red blood cell count were noticed. Normocytic 


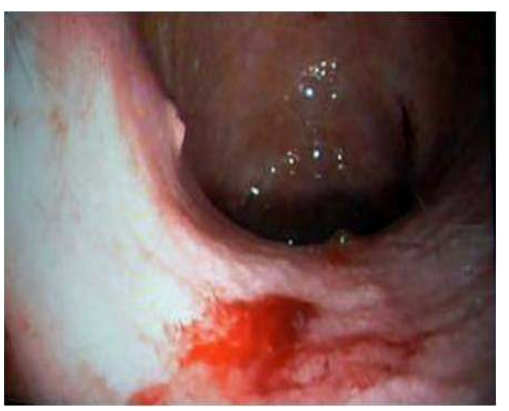

Figure-1. Ulceration in proximal portion of duodenum

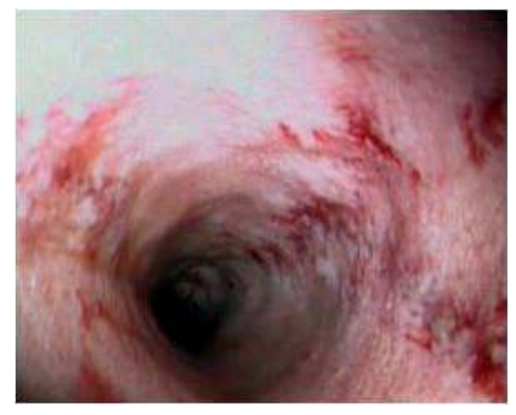

Figure-1a. Ulceration in descending portion of duodenum

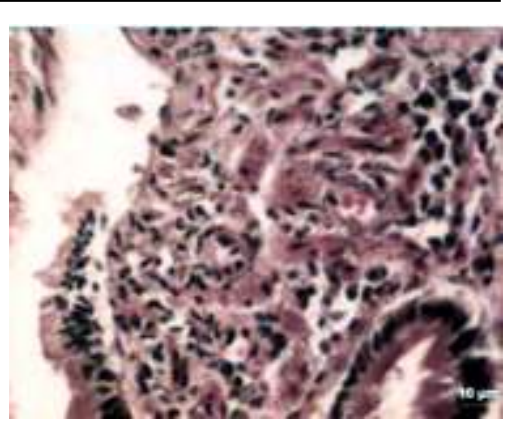

Figure-2. Discontinuvity in villus mocosa with moderat MNC infiltration $\mathrm{H} \& \mathrm{E} B \mathrm{Bar}=10 \mu \mathrm{m}$ normochromic anaemia observed in dogs with duodenal ulcer could be due to short term gastro intestinal blood loss [19].

A significant decrease in the albumin value (Table-1) was noticed. Jergens et al. [15] stated that hypoalbuminia in duodenal ulcer might be due to blood loss, ulceration and malabsorption of nutrients.

The endoscopic appearance of duodenum in healthy animals showed velvetty or slightly grainy, smooth and uniform pink color. Endoscopic findings of duodenal ulcer showed hyperemic mucosa and duodenal ulceration in all the seven dogs (Fig. $1 \& 1 \mathrm{a}$ ), followed by $29 \%$ of the dogs had friable duodenal mucosa. Dowdle et al. [20] opined that duodenoscopy was more accurate for detecting sub clinical gastroduodenal ulceration and provided a sensitive technique for early diagnosis of mucosal lesions and ulceration in the gastroduodenal area. Richter [21] described that endoscopic appearance of duodenal ulcer appeared as deep or shallow crater and demarcated with the surrounding mucosa. Leib [22] observed that endoscopic appearance of duodenal mucosa was hyperemic and ulcerated in duodenal ulceration cases and had increased friability and granularity in non ulcerated duodenitis.

Histopathologically, all the animals revealed mucosal ulceration, loss of epithelium (Fig. 2), followed by neutrophilic and monocytic infiltration $(71 \%)$ and necrosis of duodenal epithelium (43\%) of the cases. These findings correlated with Dowdle et al.20 who stated that infiltration of neutrophil and macrophages indicated inflammation, disruption of mucosal lining and haemorrhage into the mucosa. Leib and Matz [18] reported that endoscopic examination was the best way to diagnose duodenal ulcer and multiple biopsy samples should be collected from the edges of ulcers to eliminate the presence of neoplasia.

In the present study, cytological examination revealed normal cluster of epithelial cells in healthy animals and vacuolar degeneration of epithelial cells with mononuclear cell (MNC) infiltration in duodenal ulcer. Jergen et al. [23] reported that cytologic examination of exfoliative specimen obtained during endoscopy was a useful and reliable adjunct to histologic examination of biopsy specimen in gastro intestinal tract disease. There were no significant changes in bacterial counts. In faecal examination no parasites were seen.

\section{Conclusion}

Duodenal ulcer can be successfully managed if diagnosed and treated earlier. Duodenoscopy is very much useful for detecting duodenal ulceration and provided a sensitive technique for early diagnosis of mucosal lesions and ulceration.

\section{Acknowledgements}

Authors are grateful to the Dean and Head of the Department Madras Veterinary College, Chennai for providing all facilities for the study.

\section{Competing interest}

Authors declare that they have no competing interest.

\section{References}

1. Cave, N.J. (2003). Chronic inflammatory disorders of gastrointestinal tract of companion animals. New Zealand Veterinary Journal, 51:262-274.

2. Jergens, A.E., Moore, F.M., Haynes, J.S. and Miler, A.K.G. (1992a). Idiopathic inflammatory bowel disease in dogs and cats: 84 cases (1987-1990). Journal of the American Veterinary Medical Association, 201:1603-1608.

3. Zoran, L.D. (2001). Gastroduodenoscopy in dog and cat. Veterinary Clinics of North America: Small Animal Practice, 31:631-656.

4. Spillmann, T. (2007). Endoscopy of the gastrointestinal tract when its rarely indicated. In: Proceeding of the $3^{\text {2nd }}$ WSAVA congress, Sydney 
Australia.

5. Tams, T.R. (2003). Endoscopy and Laprasocopy in Veterinary Gastroenterology. In: Hand book of small animal gastro entrology, W.B. Saunders Co., Philadelphia. Pp 97-117.

6. Williams, D.A. (2004). Gastrointestinal endoscopy in dogs and cats. In: Proceeding of the $29^{\text {th }}$ WSAVA congress, Rhodes Greece.

7. Tams, T.R. (1999). In: Small animal endoscopy, 2 edn C.V. Mosby Company, St.Luis. Pp 175-176; 98-99.

8. Mansell, J. and WIllward, M.D. (2003). Biopsy of the gastro intestinal tract. Veterinary Clinics of North America: Small Animal Practice, 33:1099-1116.

9. Sancho, M.G., F.R. Franco, A. Sainz, Mancho, C.and Rodriguez, A. (2007). Evaluation of clinical macroscopic and histopathologic response to treatment in non hypoproteinemia dogs with lymphocytic plasmacytic enteritis. Journal of Veterinary Internal Medicine, 21:11-17.

10. Day, M.J., Bilzer, T., Mansell, J., Wilcock, B., Hall, E.J., Jergens, A., Minami, T., Willard, M. and Washabau, R. (2008). Histopathological standards for the diagnosis of gastro intestinal inflammation in endoscopic biopsy samples from the dogs and cat: A report from the world small animal veterinary association gastrointestinal standardization group. Journal of Comparative Pathology, S1-S43.

11. Strombeck, D.R. (1996). Small and large intestine normal structure and function. In stomberk's small animal gastroenterology, $3^{\text {rd }}$ (edn) W.G. Guilford, S.A. Center, D.R. Strombeck, D.A. William and D.J. Meyer, W.B. Saunders, Philadelphia. Pp 1318-1350.

12. Lynch, T.M., Morris, T.H., Dix, J. and Nelson, P.R. (1999). Bacterial counts in canine duodenal fluid after exposure to saline, sodium bicarbonate and hypertonic dextrose solutions used to maintain patency of chronically implanted catheters. Laboratory Animals, 33: 143-148.

13. Broussard, J.D. (2003). Optimal faecal assessment. Clinical Techniques in Small Animal Practice, 18:218-230.

14. Snedecor, G.W. and Cohran, W.G. (1994).
Statistical Methods. $8^{\text {th }}$ ed. Iowa State University Press, USA.

15. Jergens, A.E., Moore, F.M. and March, P. (1992). Idiopathic inflammatory bowel disease associated with gastro duodenal ulceration - erosion: A report of nine cases in the dog and cat. Journal of the American Animal Hospital Association, 28:21-26.

16. Hinton, L.E., McLoughlin, M.A., Johnson, S.E. and Weisbrode, S.E. (2002). Spontaneous gastro duodenal perforation in 16 dogs and seven cats (1982-1999). Journal of the American Veterinary Medical Association, 38:176-187.

17. Dachler, M.H. (1986). Transmural pyloric perforation associated with naproxen administration in a dog. Journal of the American Veterinary Medical Association, 189:694-695.

18. Leib, M.S. and Matz, M.E. (1997). Disease of the intestine. In practical small animal internal medicine (edt) M.S. Leib and W.E. Monvoe, W.B. Saunders, Philadelphia. Pp 685-690.

19. Willace, M.S., Zawie, D.A. and Garvey, M.S. (1990). Gastric ulceration in the dog secondary to the use of non steroidal anti-inflammatory drugs. Journal of the American Animal Hospital Association, 26:467-472.

20. Dowdle, S.M., Joubert, K.E., Lambrechts, N.E., Lobetti, R.G. and Pardini, A.D. (2003). The prevalence of sub clinical gastro duodenal ulceration in dachands with intervertebral disc prolapse. South African Veterinary Association, 74:77-81.

21. Richter, K.P. (1992). An introduction to endoscopy instrumentation and technique. Veterinary Medicine, 1165-1175.

22. Leib, M.S. (1997). Disease of stomach In practical small animal internal medicine (edt) M.S. Leib and W.E. Monvoe, W.B. Saunders, Philadelphia. Pp 640-655.

23. Jergens, A.E., Andreasen, C.B., Hagemoser, W.A., Ridgway, J. and Campbell, K.L. (1998). Cytologic examination of exfoliative specimen obtained during endoscopy for diagnosis of GI tract disease in dogs and cats. Journal of the American Veterinary Medical Association, 213:1755-1759.

\footnotetext{
$* * * * * * * *$
} 